\title{
Detection of Major Cardioembolic Sources in Real-World Patients with Ischemic Stroke or Transient Ischemic Attack of Undetermined Cause
}

\author{
Gerlinde van der Maten ${ }^{a, b} \quad$ Jorieke M.B. Reimer ${ }^{a} \quad$ Matthijs F.L. Meijs ${ }^{c}$ \\ Clemens von Birgelen ${ }^{b, c}$ Marjolein G.J. Brusse-Keizer ${ }^{b, d}$ \\ Heleen M. den Hertog ${ }^{\mathrm{e}}$ \\ aDepartment of Neurology, Medisch Spectrum Twente, Enschede, The Netherlands; ${ }^{\mathrm{b}}$ Department of \\ Health Technology and Services Research, Faculty of Behavioural, Management and Social Sciences, Technical \\ Medical Centre, University of Twente, Enschede, The Netherlands; ' ${ }^{C}$ Department of Cardiology, Thoraxcentrum \\ Twente, Medisch Spectrum Twente, Enschede, The Netherlands; ${ }^{d}$ Medical School Twente, Medisch Spectrum

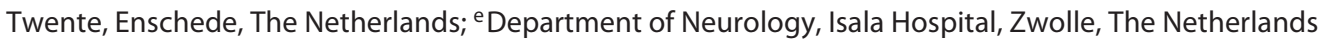

\section{Keywords}

Atrial fibrillation · Brain ischemia · Echocardiography ·

Embolism · Ischemic stroke $\cdot$ Transient ischemic attack

\begin{abstract}
Background/Aim: Current guidelines recommend transthoracic echocardiography (TTE) and ambulatory rhythm monitoring following ischemic stroke or transient ischemic attack (TIA) of undetermined cause for identifying cardioembolic sources (CES). Due to ongoing controversies about this routine strategy, we evaluated its yield in a real-world setting. Methods: In a tertiary medical center, we retrospectively evaluated consecutive patients with ischemic stroke or TIA of undetermined cause, who (after standard work-up) underwent TTE, ambulatory rhythm monitoring, or both. CES were classified as major if probably related to ischemic events and warranting a change of therapy. Results: Between January 2014 and December 2017, 674 patients had ischemic stroke or TIA of undetermined cause. Of all 484 patients (71.8\%) who underwent TTE, 9 (1.9\%) had a major CES. However, 7 of them had already been identified for cardiac evaluation due to new major electrocardiographic abnor-
\end{abstract}

karger@karger.com www.karger.com/cee

Karger $\stackrel{\text { ' }}{5}$

GOPEN ACCESS
(C) 2021 The Author(s)

Published by S. Karger AG, Basel

This article is licensed under the Creative Commons AttributionNonCommercial-NoDerivatives 4.0 International License (CC BYNC-ND) (http://www.karger.com/Services/OpenAccessLicense). Usage and distribution for commercial purposes as well as any distribution of modified material requires written permission. malities or cardiac symptoms. Thus, only 2 patients $(0.4 \%)$ truly benefitted from unselected TTE screening. Ambulatory rhythm monitoring was performed in 411 patients (61.0\%) and revealed AF in 10 patients (2.4\%). Conclusion: Detecting a major CES is essential because appropriate treatment lowers the risk of recurrent stroke. Nonetheless, in this realworld study that aimed at routine use of TTE and ambulatory rhythm monitoring in patients with ischemic stroke or TIA of undetermined cause, the prevalence of major CES was low. Most patients with major CES on TTE already had an indication for referral to a cardiologist, suggesting that major CES might also have been identified with a much more selective use of TTE.

(C) 2021 The Author(s)

Published by S. Karger AG, Basel

\section{Introduction}

Of all ischemic strokes, $20-30 \%$ are related to a cardioembolic source (CES) [1,2], including atrial fibrillation (AF) and a variety of structural cardiac and ascending aortic pathologies [3]. Major CES have well-established pathophysiological relations to ischemic stroke and re- 
quire a change of therapy in order to reduce the risk of recurrent stroke, while minor CES might not necessarily be (directly) related to ischemic stroke and generally do not require changing therapy [3]. After standard in-hospital work-up of patients with ischemic stroke, the cause of the event remains unknown in 1 out of 4 patients [2]. In search of a major CES, these patients usually are referred for further cardiac assessment with echocardiography and ambulatory rhythm monitoring.

Echocardiography is the main imaging modality for detecting structural cardiac abnormalities [3], but its indication in patients with ischemic stroke remains a matter of debate $[4,5]$. Most international guidelines advise routine echocardiographic evaluation in the setting of ischemic stroke or transient ischemic attack (TIA) of undetermined cause [3, 6-8]. However, the yield of transthoracic echocardiography (TTE) is uncertain. In previous studies it varied from 3 to $37 \%$, but many of these studies assessed relatively small and inhomogeneous patient populations, and the used definitions of clinically relevant CES were dissimilar [5, 9-15]. In addition, current guidelines recommend rhythm monitoring for at least $24 \mathrm{~h}$ for detecting $\mathrm{AF}$ in patients with ischemic stroke. While these guidelines also consider more prolonged ambulatory rhythm monitoring to be reasonable, they specify neither the patient population to which this may apply nor the preferred method to be used $[6,8]$.

\section{Aims}

Our aim was to determine the rate of major CES detected by routine use of TTE and ambulatory rhythm monitoring in a consecutive series of patients with ischemic stroke or TIA of undetermined cause. For that purpose, the study applied a clear definition of clinically relevant findings, which was based on implications with a change of therapy.

\section{Subjects and Methods}

\section{Study Design}

At Medisch Spectrum Twente, a tertiary teaching hospital in the Netherlands, we assessed the clinical data on all patients aged 18 years or older from January 2014 to December 2017. Patients were included if they were diagnosed with ischemic stroke or TIA of undetermined cause after a standard work-up that consisted of medical history, physical examination, routine laboratory assessment, 12-lead electrocardiogram (ECG), continuous ECG monitoring for at least $24 \mathrm{~h}$, brain imaging with computed tomography (CT) or magnetic resonance imaging (MRI) and carotid artery imaging with Doppler ultrasonography, CT angiography, or MR angiography. Ischemic stroke or TIA of undetermined cause due to
Table 1. Potential cardioembolic sources

Therapy

Major cardioembolic sources

Atrial fibrillation $\quad$ OAC

Thrombus in the LA, LAA, or LV OAC

LV aneurysm $\quad$ OAC

Dilated cardiomyopathy with $\mathrm{LVEF}<35 \% \quad$ OAC

Mitral valve stenosis OAC

Endocarditis Antibiotics

Intracardiac tumor Surgery

Minor cardioembolic sources

Mitral valve prolapse

Severe mitral annular calcification

Moderate or severe aortic valve stenosis

Aortic arch atheromatous plaques

Patent foramen ovale

Atrial septal aneurysm

LA, left atrium; LAA, left atrial appendage; LV, left ventricle; LVEF, left ventricular ejection fraction; OAC, oral anticoagulation.

a negative evaluation was diagnosed according to the Trial of Org 10172 in Acute Stroke Treatment (TOAST) criteria [16]. Patients were retrospectively identified from an electronic stroke database. Results from neurologic and cardiac investigations and therapeutic consequences were collected from original electronic patient files.

\section{TTE Methods}

The patients underwent TTE assessment by an experienced sonographer according to the European Association of Cardiovascular Imaging (EACVI) recommendations. They were imaged in the left lateral decubitus position, using commercially available TTE devices (EPIQ, iE33 or CX50 systems; Philips Medical Systems, The Netherlands). Images were obtained with a 5-MHz transducer in the parasternal and apical views (standard long-axis, shortaxis, 2-chamber, and 4-chamber images). Standard two-dimensional, color Doppler, and both pulsed and continuous wave Doppler data were stored. All images were analyzed by board-certified cardiologists for left ventricular function, regional wall motion abnormalities, relevant valvular disease, atrial volume, and the presence of thrombi or tumors, using IntelliSpace Cardiovascular software (ISCV version 1.2; Philips Medical Systems Nederland B.V., Eindhoven, The Netherlands). Major CES were defined as findings that presumably were the CES of stroke and provided an indication for a change of therapy. Minor CES were defined as possible CES of stroke without therapeutic consequences $[2,3]$. An overview of the major and minor CES and corresponding recommended therapy changes is provided in Table 1.

\section{Ambulatory Rhythm Monitoring Methods}

The patients were monitored with a 24-h 3-channel (5-lead) Philips DigiTrak XT Holter monitoring system (Philips Medical Systems Nederland B.V.), a 7-day 1-channel (2-lead) Vitaphone 3100BT event loop recorder (Vitaphone GmbH, Mannheim, Ger- 


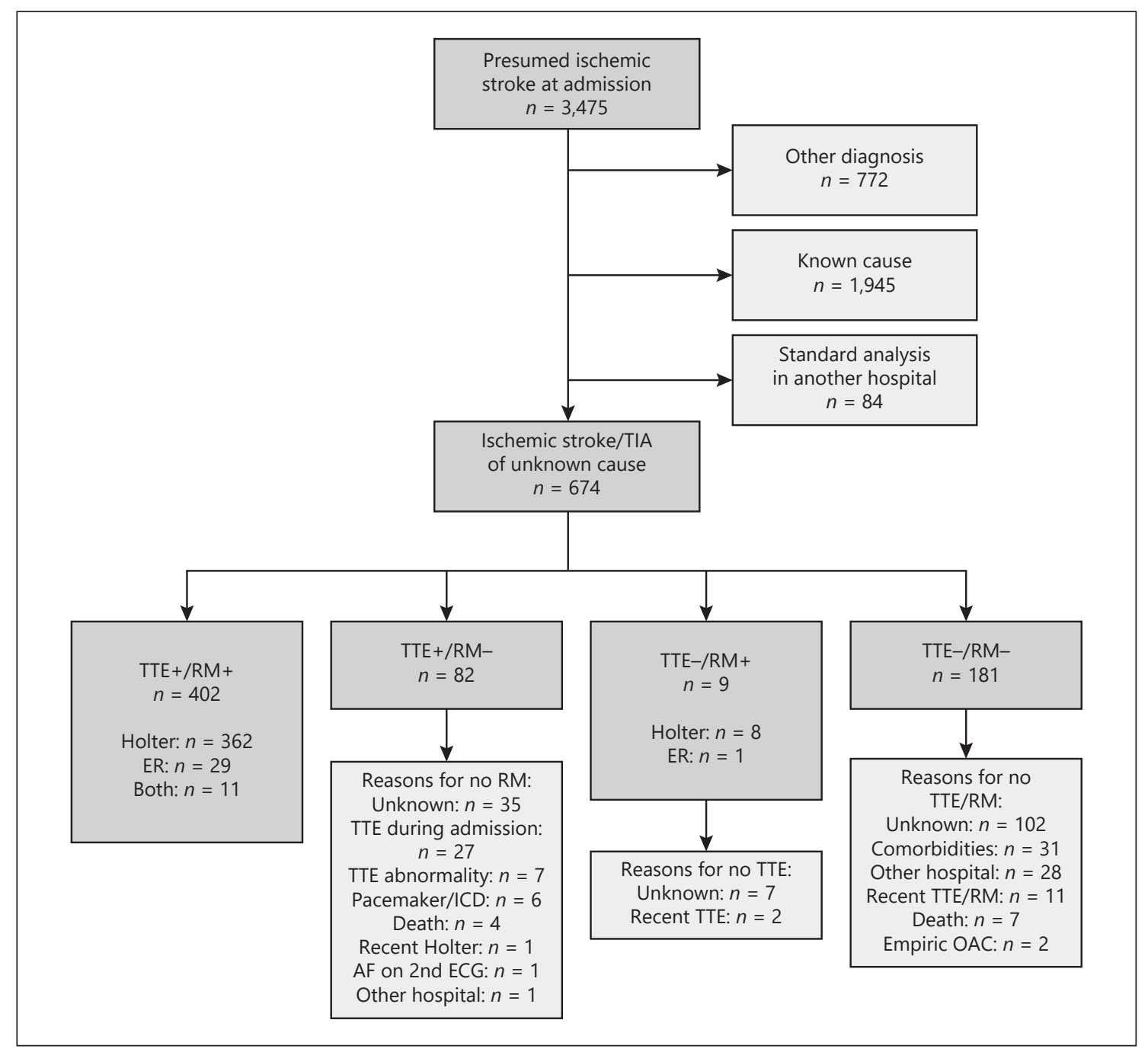

Fig. 1. Flowchart of patient inclusion. TTE, transthoracic echocardiography; RM, (ambulatory) rhythm monitoring; ER, event recorder; ICD, implantable cardioverter-defibrillator; AF, atrial fibrillation; OAC, oral anticoagulants.

many), or both, at the discretion of the treating cardiologist. The patients were asked to note when they had symptoms of chest pain, palpitations, or dyspnea. Patients with a Vitaphone event loop recorder could initiate recording when experiencing cardiac complaints. In addition, automatic AF detection was triggered based on R-R interval variability calculated by an integrated algorithm. All recorded episodes were analyzed by a board-certified cardiologist for AF or other arrhythmias, using Zymed analysis software (Philips Medical Systems Nederland B.V.) in case of Holter monitoring or the Vitaphone integrated software in case of event recording. AF was defined as a sequence of at least $30 \mathrm{~s}$ of irregular $\mathrm{R}-\mathrm{R}$ intervals in the absence of distinct repeating $\mathrm{P}$ waves but presence of irregular atrial activity.

\section{Outcome Measures and Statistical Analysis}

The main study outcomes of interest were the rate of patients with a major or minor CES on TTE or ambulatory rhythm moni- toring and the proportion of patients with a change of therapy. The data are presented as numbers and frequencies, mean $\pm \mathrm{SD}$, or median and interquartile range (IQR), as appropriate. All analyses were performed with SPSS, version 24 (IBM Corp., Armonk, NY, USA).

\section{Results}

From January 2014 until December 2017, 3,475 patients were admitted to the stroke unit of our medical center. A total of 674 patients had ischemic stroke or TIA of unknown cause; $484(71.8 \%)$ of these patients underwent TTE, and 411 patients (61.0\%) had an evaluation with ambulatory rhythm monitoring. In 181 (26.9\%) of the el- 
igible patients, no further cardiac investigation was performed (Fig. 1). Table 2 presents the characteristics of the included patients.

\section{Yield of TTE}

TTE revealed a major CES in $9 / 484$ patients (1.9\%) and a minor CES in 20/484 patients (4.1\%). Further details are presented in Table 3. In 1 patient, mobile thrombi in the aortic arch were seen, which had not been classified as a major CES beforehand but were considered as such. Of all 9 patients with major CES on TTE, 6 had major ECG abnormalities that warranted echocardiographic assessment. Of the remaining 3 patients, 1 patient had severe exertional dyspnea that warranted further cardiac evaluation. Additional characteristics of these patients are shown in Table 4.

\section{Yield of Ambulatory Rhythm Monitoring}

Ambulatory rhythm monitoring revealed previously unknown $\mathrm{AF}$ in $10 / 411$ patients (2.4\%) of whom 370 patients underwent 24 -h Holter monitoring, 30 had a 7 -day event recorder, and 11 had both. Holter monitoring showed AF in 10 patients (2.6\%), but 7-day event recording detected AF in none of the patients. The median duration between hospital admission and Holter monitoring was 40.5 (IQR 28.0-65.25) days, and the median duration between admission and 7-day event recording was 64.5 (IQR 40.5-110.0) days. Online supplementary Table 1 (see www. karger.com/doi/10.1159/000512743 for all online suppl. material) presents additional details of these patients.

\section{Therapeutic Consequences}

In all patients with a major CES there was a change of therapy. Further details are presented in Table 3.

\section{Discussion}

In this study on consecutive patients with ischemic stroke or TIA of undetermined cause, TTE revealed a major CES in $1.9 \%$ of the patients, and ambulatory rhythm monitoring detected $\mathrm{AF}$ in $2.4 \%$ of the assessed patients. Most patients with major CES on TTE (78\%) already had an indication for further cardiac evaluation, based on symptoms or new ECG abnormalities. Therefore, it is fair to assume that the vast majority of these patients also would have been identified with a much more selective use of TTE.

Several earlier studies assessed the yield of echocardiography in patients with stroke [5, 9-15], but compari-
Table 2. Characteristics of the included patients

\begin{tabular}{|c|c|c|}
\hline & $\begin{array}{l}\text { TTE } \\
(n=484)\end{array}$ & $\begin{array}{l}\text { Rhythm } \\
\text { monitoring } \\
(n=411)\end{array}$ \\
\hline Male sex & $266(54.8)$ & $225(54.7)$ \\
\hline Age, years & $65.7 \pm 13.8$ & $66.0 \pm 13.3$ \\
\hline \multicolumn{3}{|l|}{ Cardiovascular risk factors } \\
\hline Hypertension & $286(59.1)$ & $237(57.7)$ \\
\hline Diabetes & $119(24.6)$ & $100(24.3)$ \\
\hline Dyslipidemia & $391(80.8)$ & $338(82.2)$ \\
\hline Smoking & $141(29.1)$ & $117(28.5)$ \\
\hline \multicolumn{3}{|l|}{ History of } \\
\hline TIA & $47(9.7)$ & $38(9.2)$ \\
\hline Ischemic stroke & $51(10.5)$ & $42(10.2)$ \\
\hline Myocardial infarction & $52(10.7)$ & $40(9.7)$ \\
\hline \multicolumn{3}{|l|}{ Type of event } \\
\hline TIA & $93(19.2)$ & $81(19.7)$ \\
\hline Ischemic stroke & $391(80.8)$ & $330(80.3)$ \\
\hline Baseline NIHSS score & $3(2-5)$ & $3(2-5)$ \\
\hline \multicolumn{3}{|l|}{ Localization } \\
\hline Cortical & $329(68.0)$ & $271(65.9)$ \\
\hline Subcortical & $146(30.2)$ & $131(31.9)$ \\
\hline Lacunar & 0 & 0 \\
\hline Border zone & $1(0.2)$ & $2(0.5)$ \\
\hline Multiple locations & $8(1.7)$ & $7(1.7)$ \\
\hline
\end{tabular}

Data are presented as $n(\%)$ except for age (mean \pm SD) and NIHSS (median [interquartile range]). TTE, transthoracic echocardiography; TIA, transient ischemic attack; NIHSS, National Institute of Health Stroke Scale.

sons with the findings of the present study are hampered by several factors. Among the previous studies, the yield of echocardiography ranged from 3 to $37 \%$, which is largely related to substantial differences in study populations. Most studies also included patients with a known cause of embolism, or nonischemic stroke [5, 9-14]. An additional factor with major impact on the yield is the evolution of which findings are classified as "therapy changers." For instance, some previous studies reported spontaneous echo contrast [11], or dilated cardiomyopathy or left ventricular wall dyskinesia regardless of the left ventricular ejection fraction $[10,13]$, as reasons for changing therapy. Current evidence does not suggest changing therapy based on these pathologies [3].

The findings of the present study suggest that routine screening with TTE in patients with ischemic stroke or TIA of undetermined cause is inefficient, since a major CES was found in 9 patients (1.9\%). Furthermore, 7 of these 9 patients had new major ECG abnormalities or complaints of severe exertional dyspnea. Referring these 
Table 3. Potential cardioembolic sources found by TTE or rhythm monitoring, and therapeutic consequences

\begin{tabular}{|c|c|c|c|c|}
\hline & \multirow[t]{2}{*}{$n(\%)$} & \multicolumn{3}{|c|}{ Type of treatment } \\
\hline & & $\mathrm{OAC}$ & antibiotics & surgery \\
\hline \multicolumn{5}{|l|}{$\operatorname{TTE}(n=484)$} \\
\hline Major risk sources & $9(1.9)$ & 7 & 2 & 0 \\
\hline Thrombus in the LA, LAA, or LV & $1(0.2)$ & 1 & 0 & 0 \\
\hline LV aneurysm & 0 & - & - & - \\
\hline LV aneurysm and DCM with LVEF $<35 \%$ & $1(0.2)$ & 1 & 0 & 0 \\
\hline DCM with LVEF $<35 \%$ & $4(0.8)$ & 4 & 0 & 0 \\
\hline Mitral valve stenosis & 0 & - & - & - \\
\hline Endocarditis & $2(0.4)$ & 0 & 2 & 0 \\
\hline Intracardiac tumors & 0 & - & - & - \\
\hline Mobile thrombi in the aortic $\operatorname{arch}^{1}$ & $1(0.2)$ & 1 & 0 & 0 \\
\hline Minor risk sources & $20(4.1)$ & & & \\
\hline Mitral valve prolapse & $3(0.6)$ & & & \\
\hline Severe mitral annular calcification & 0 & & & \\
\hline Moderate aortic valve stenosis & $3(0.6)$ & & & \\
\hline Severe aortic valve stenosis & 0 & & & \\
\hline Aortic arch atheromatous plaques & $1(0.2)$ & & & \\
\hline Patent foramen ovale & $12(2.5)$ & & & \\
\hline Atrial septal aneurysm & $1(0.2)$ & & & \\
\hline \multicolumn{5}{|l|}{ Ambulatory rhythm monitoring $(n=411)$} \\
\hline Atrial fibrillation & $10(2.4)$ & 10 & 0 & 0 \\
\hline
\end{tabular}

Data are presented as $n(\%)$. TTE, transthoracic echocardiography; LA, left atrium; LAA, left atrial appendage; LV, left ventricle; DCM, dilated cardiomyopathy; LVEF, left ventricular ejection fraction; OAC, oral anticoagulation. ${ }^{1}$ Considered a major cardioembolic source with indication for oral anticoagulation although not classified beforehand.

Table 4. Characteristics of the patients with a major cardioembolic source on TTE

\begin{tabular}{lllllll}
\hline No. & Sex & $\begin{array}{l}\text { Age, } \\
\text { years }\end{array}$ & TTE findings & Complaints & ECG & Brain imaging \\
\hline 1. & M & 48 & DCM with LVEF $<35 \%$ & Chest pain & Negative T in leads I, aVL, V4-V6 & MRI: ischemia of the pons \\
\hline 2. & M & 70 & DCM with LVEF $<35 \%$ & Palpitations & $\begin{array}{l}\text { LBBB, ST elevation in leads V1-V3, } \\
\text { ST depression in leads V5-V6 }\end{array}$ & CT: no recent ischemia \\
\hline 3. & F & 36 & DCM with LVEF $<35 \%$ & Exercise dyspnea & Normal & $\begin{array}{l}\text { MRI: recent ischemia in the left MCA } \\
\text { territory }\end{array}$ \\
\hline 4. & M & 53 & DCM with LVEF $<35 \%$ & Exercise dyspnea & LBBB & CT: no recent ischemia \\
\hline 5. & M & 57 & $\begin{array}{l}\text { DCM with LVEF }<35 \%+\text { LV } \\
\text { aneurysm }\end{array}$ & No cardiac complaints & $\begin{array}{l}\text { No R wave progression in anterior } \\
\text { leads }\end{array}$ & $\begin{array}{l}\text { CT: recent ischemia in the left MCA } \\
\text { territory }\end{array}$ \\
\hline 6. & F & 86 & Endocarditis & Exercise dyspnea & Normal & CT: no recent ischemia \\
\hline 7. & M & 66 & Endocarditis & Fever chills, chest pain & $\begin{array}{l}\text { Q waves in leads II, III, aVF, ST } \\
\text { depression in leads V2-V5 }\end{array}$ & $\begin{array}{l}\text { MRI: diffuse bilateral spreading of } \\
\text { areas of recent ischemia }\end{array}$ \\
\hline 8. & F & 44 & Left ventricular thrombus & No cardiac complaints & Q waves in leads V1-V3 & $\begin{array}{l}\text { MRI: recent ischemia in the right } \\
\text { MCA territory }\end{array}$ \\
\hline 9. & F & 78 & Mobile aortic thrombi & No cardiac complaints & Normal & $\begin{array}{l}\text { CT angiography: occlusion of the M3 } \\
\text { segment indicating cortical ischemia }\end{array}$ \\
\hline
\end{tabular}

TTE, transthoracic echocardiography; ECG, electrocardiogram; DCM, dilated cardiomyopathy; LVEF, left ventricular ejection fraction; MRI, magnetic resonance imaging; LBBB, left bundle branch block; CT, computed tomography; MCA, middle cerebral artery. 
patients to a cardiologist should be considered usual medical care. Thus, standard work-up would already have resulted in identifying CES in most of these patients, while in 2 patients, representing $0.4 \%$ of all patients who underwent TTE, a major CES would have been missed. Our results suggest that, with data from large prospective studies, the use of TTE in patients with ischemic stroke of undetermined cause could be optimized to reduce the number of futile examinations.

Intuitively, one may feel that transesophageal echocardiography (TEE) could be preferred for diagnosing CES, because it has a higher sensitivity for detecting left atrial appendage thrombi, complex aortic plaques, and vegetations. However, as an initial screening tool after ischemic stroke, TEE usually has no added value, because left atrial appendage thrombi are almost exclusively present in patients with AF [3], and oral anticoagulants do not lower the risk of recurrent stroke in patients with complex aortic plaques [17]. In addition, the diagnosis of infective endocarditis is based on the Duke criteria. When endocarditis is suspected, TTE is recommended as the first diagnostic modality, which has a sensitivity of approximately $60 \%$ for detecting a vegetation. However, if TTE results are negative and the clinical suspicion of endocarditis remains high, further evaluation with TEE, which has a sensitivity of $85-90 \%$ for detecting a vegetation, is necessary [3]. Nonetheless, patients with a high clinical suspicion of endocarditis were not considered to have ischemic stroke of undetermined cause and, thus, were not eligible for our study.

In the present study, ambulatory rhythm monitoring detected AF in $2.4 \%$ of the patients, and no more AF was detected in the small group of patients with 7-day event recording as compared to 24 -h Holter monitoring. The longer period of time between the ischemic event and the initiation of the 7-day event recording might have played a role. A meta-analysis of Holter monitoring during 1-7 days showed a much higher detection rate of $10.7 \%$ [18]. Also, several other studies have demonstrated that AF is detected more frequently by prolonged and early-initiated monitoring $[19,20]$, suggesting approaches to improve AF detection.

\section{Strengths and Limitations}

The present study evaluated the results of both TTE and ambulatory rhythm monitoring in a relatively large group of patients with ischemic stroke of undetermined cause. In addition, we only classified cardiovascular pathologies as major CES if they were associated with a change of therapy.

Cardioembolic Sources in Ischemic Stroke of Undetermined Cause
Our study also has limitations. First, it is a single-center study with a retrospective design. This limits generalization of the findings. Second, $28 \%$ of the eligible patients did not undergo TTE and 39\% had no additional ambulatory rhythm monitoring. Although cardiac assessment is part of clinical routine if standard work-up does not reveal the cause of ischemic stroke or TIA, physicians sometimes refrain from further analyses in individual patients, which may have resulted in over- or underrepresentation of findings. Third, the majority of patients underwent the shortest acceptable duration of ambulatory rhythm monitoring, and the time from ischemic event to initiation of ECG monitoring was relatively long. Fourth, the prevalence of patent foramen ovale (PFO) may be an underrepresentation, because patients that were not eligible for PFO closure at that time did not undergo agitated saline-enhanced echocardiography. PFO closure should only be considered in patients with cryptogenic embolism and a PFO with a high probability of a causal relationship, based on patient age, cardiovascular risk factors, and PFO characteristics $[21,22]$. Evidence for this recommendation became available after publication of the results of the CLOSE, RESPECT, and Gore REDUCE trials, which was at the end of the inclusion period of our study [23-25].

\section{Conclusions}

Detecting a major CES is essential because it often leads to a change of therapy in order to reduce the risk of recurrent stroke. In this real-world study that aimed at routine use of TTE and ambulatory rhythm monitoring in patients with ischemic stroke or TIA of undetermined cause, the prevalence of major CES was low. Most patients with major CES detected by TTE already had an indication for referral to a cardiologist, which suggests that the majority of these pathologies would also have been identified with a much more selective use of TTE. These data call current cardiac screening into question. A large-scale, prospective multicenter study is warranted to provide data that may help develop a more efficient approach.

\section{Statement of Ethics}

This retrospective study is exempt from Ethics Committee approval. According to Dutch law, this study did not require a formal assessment by a medical Ethics Committee because the patients were not subjected to interventions other than in the context of standard medical care or imposed upon a particular course of conduct. 


\section{Conflict of Interest Statement}

C.v.B. reports that the research department of Thoraxcentrum Twente has received institutional research grants provided by Abbott Vascular, Biotronik, Boston Scientific, and Medtronic, outside the present research. All other authors have no conflicts of interest to declare.

\section{Funding Sources}

The authors received no specific funding for this work.

\section{Author Contributions}

G.v.d.M. and J.M.B.R.: acquisition, analysis and interpretation of the data, drafting of the manuscript, and final approval of the manuscript. M.F.L.M.: interpretation of the data, revising the manuscript, and final approval of the manuscript. C.v.B.: design, major revision and final approval of the manuscript. M.G.J.B.-K.: statistical interpretation of the data, revising the manuscript, and final approval of the manuscript. H.M.d.H.: conception and design of the work/manuscript, interpretation of the data, revising the manuscript, and final approval of the manuscript.

\section{References}

1 Kolominsky-Rabas PL, Weber M, Gefeller O, Neundoerfer B, Heuschmann PU. Epidemiology of ischemic stroke subtypes according to TOAST criteria: incidence, recurrence, and long-term survival in ischemic stroke subtypes: a population-based study. Stroke. 2001 Dec;32(12):2735-40.

2 Hart RG, Diener HC, Coutts SB, Easton JD, Granger CB, O’Donnell MJ, et al.; Cryptogenic Stroke/ESUS International Working Group. Embolic strokes of undetermined source: the case for a new clinical construct. Lancet Neurol. 2014 Apr;13(4):429-38.

3 Pepi M, Evangelista A, Nihoyannopoulos P, Flachskampf FA, Athanassopoulos G, Colonna $P$, et al.; European Association of Echocardiography. Recommendations for echocardiography use in the diagnosis and management of cardiac sources of embolism: European Association of Echocardiography (EAE) (a registered branch of the ESC). Eur J Echocardiogr. 2010 Jul;11(6):461-76.

4 Yu EH, Lungu C, Kanner RM, Libman RB. The use of diagnostic tests in patients with acute ischemic stroke. J Stroke Cerebrovasc Dis. 2009 May-Jun;18(3):178-84.

5 Gaudron M, Bonnaud I, Ros A, Patat F, de Toffol B, Giraudeau B, et al. Diagnostic and therapeutic value of echocardiography during the acute phase of ischemic stroke. J Stroke Cerebrovasc Dis. 2014 Sep;23(8):2105-9.

6 European Stroke Organisation (ESO) Executive Committee; ESO Writing Committee. Guidelines for management of ischaemic stroke and transient ischaemic attack 2008. Cerebrovasc Dis. 2008;25(5):457-507.

7 Saric M, Armour AC, Arnaout MS, Chaudhry FA, Grimm RA, Kronzon I, et al. Guidelines for the Use of Echocardiography in the Evaluation of a Cardiac Source of Embolism. J Am Soc Echocardiogr. 2016 Jan;29(1):1-42.

8 Powers WJ, Rabinstein AA, Ackerson T, Adeoye OM, Bambakidis NC, Becker K, et al.; American Heart Association Stroke Council. 2018 Guidelines for the Early Management of Patients with Acute Ischemic Stroke: A Guideline for Healthcare Professionals from the American Heart Association/American Stroke Association. Stroke. 2018 Mar;49(3):e46-110.
9 Sansoy V, Abbott RD, Jayaweera AR, Kaul S. Low yield of transthoracic echocardiography for cardiac source of embolism. Am J Cardiol. 1995 Jan;75(2):166-9.

10 Yaghoubi E, Nemati R, Aghasadeghi K, Borhani Haghighi A. The diagnostic efficiency of transesophageal compared to transthoracic echocardiographic findings from 405 patients with ischemic stroke. J Clin Neurosci. 2011 Nov;18(11):1486-9.

11 Ahmad O, Ahmad KE, Dear KB, Harvey I, Hughes A, Lueck CJ. Echocardiography in the detection of cardioembolism in a stroke population. J Clin Neurosci. 2010 May; 17(5):561-5.

12 Wolber T, Maeder M, Atefy R, Bluzaite I, Blank $\mathrm{R}$, Rickli H, et al. Should routine echocardiography be performed in all patients with stroke? J Stroke Cerebrovasc Dis. 2007 Jan-Feb;16(1): $1-7$.

13 Abreu TT, Mateus S, Correia J. Therapy implications of transthoracic echocardiography in acute ischemic stroke patients. Stroke. 2005 Jul;36(7):1565-6.

14 Menon BK, Coulter JI, Bal S, Godzwon C, Weeks S, Hutchison S, et al. Acute ischaemic stroke or transient ischaemic attack and the need for inpatient echocardiography. Postgrad Med J. 2014 Aug;90(1066):434-8.

15 de Bruijn SF, Agema WR, Lammers GJ, van der Wall EE, Wolterbeek R, Holman ER, et al. Transesophageal echocardiography is superior to transthoracic echocardiography in management of patients of any age with transient ischemic attack or stroke. Stroke. 2006 Oct;37(10): 2531-4.

16 Adams HP Jr, Bendixen BH, Kappelle LJ, Biller J, Love BB, Gordon DL, et al. Classification of subtype of acute ischemic stroke. Definitions for use in a multicenter clinical trial. TOAST. Trial of Org 10172 in Acute Stroke Treatment. Stroke. 1993 Jan;24(1):35-41.

17 Amarenco P, Davis S, Jones EF, Cohen AA, Heiss WD, Kaste M, et al.; Aortic Arch Related Cerebral Hazard Trial Investigators. Clopidogrel plus aspirin versus warfarin in patients with stroke and aortic arch plaques. Stroke. 2014 May;45(5):1248-57.

18 Sposato LA, Cipriano LE, Saposnik G, Ruíz Vargas E, Riccio PM, Hachinski V. Diagnosis of atrial fibrillation after stroke and transient ischaemic attack: a systematic review and meta-analysis. Lancet Neurol. 2015 Apr;14(4): 377-87.

19 Wachter R, Gröschel K, Gelbrich G, Hamann GF, Kermer P, Liman J, et al.; Find$\mathrm{AF}$ (randomised) Investigators and Coordinators. Holter-electrocardiogram-monitoring in patients with acute ischaemic stroke (Find-AFRANDOMISED): an open-label randomised controlled trial. Lancet Neurol. 2017 Apr; 16(4):282-90

20 Gladstone DJ, Spring M, Dorian P, Panzov V, Thorpe KE, Hall J, et al.; EMBRACE Investigators and Coordinators. Atrial fibrillation in patients with cryptogenic stroke. N Engl J Med. 2014 Jun;370(26):2467-77.

21 Pristipino C, Sievert H, D'Ascenzo F, Louis Mas J, Meier B, Scacciatella P, et al.; Evidence Synthesis Team; Eapci Scientific Documents and Initiatives Committee; International Experts. European position paper on the management of patients with patent foramen ovale. General approach and left circulation thromboembolism. Eur Heart J. 2019 Oct;40(38):3182-95.

22 Messé SR, Gronseth GS, Kent DM, Kizer JR, Homma S, Rosterman L, et al. Practice advisory update summary: Patent foramen ovale and secondary stroke prevention: Report of the Guideline Subcommittee of the American Academy of Neurology. Neurology. 2020 May; 94(20):876-85.

23 Mas JL, Derumeaux G, Guillon B, Massardier E, Hosseini H, Mechtouff L, et al.; CLOSE Investigators. Patent Foramen Ovale Closure or Anticoagulation vs. Antiplatelets after Stroke. N Engl J Med. 2017 Sep;377(11):1011-21.

24 Saver JL, Carroll JD, Thaler DE, Smalling RW, MacDonald LA, Marks DS, et al.; RESPECT Investigators. Long-Term Outcomes of Patent Foramen Ovale Closure or Medical Therapy after Stroke. N Engl J Med. 2017 Sep;377(11): 1022-32.

25 Søndergaard L, Kasner SE, Rhodes JF, Andersen G, Iversen HK, Nielsen-Kudsk JE, et al.; Gore REDUCE Clinical Study Investigators. Patent Foramen Ovale Closure or Antiplatelet Therapy for Cryptogenic Stroke. N Engl J Med. 2017 Sep;377(11):1033-42. van der Maten/Reimer/Meijs/ von Birgelen/Brusse-Keizer/den Hertog 